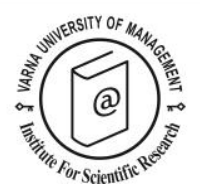

\title{
The influence of airport security procedures on the intention to re-travel
}

\author{
Saad Al-Saad ${ }^{1 *}$, Abdelkader Ababneh ${ }^{2}$ and Mohammad M. Alazaizeh ${ }^{3}$
}

Received: 06/12/2018 Accepted: 10/04/2019

\footnotetext{
${ }_{1}^{1}$ Associate Professor, Department of Travel and Tourism, Yarmouk University, Irbid 21163, Jordan

Tel. (+962) 27211111 Ex. 2267. Mobile: (+962) 791537701, Email: saed@yu.edu.jo

2 Associate Professor, Department of Travel and Tourism, Yarmouk University, Irbid 21163, Jordan

Tel. (+962) 27211111 Ex. 2287. Mobile: (+962) 776424670, Email: abdelkader@yu.edu.jo

3 Assistant Professor, Department of Tourism Management, The University of Jordan, Aqaba 77110, Jordan,

Tel. (+962) 32090450 Ex. 35133. Mobile: (+962) 791453155, Email: m.alazaizeh@ju.edu.jo

* Corresponding author

Coordinating editor: Martina González-Gallarza Granizo
}

\begin{abstract}
The purpose of this research is to examine empirically the relationships between, on the one side, awareness, feeling of comfort, of Jordanian international travellers towards airport security procedures, and on the other, their intention to re-travel. Three levels of airport security procedures were examined: standard, elevated and racial profiling/human treatment independently in one single model. A quantitative survey based on a convenience sample was conducted in Jordan. Confirmatory factor analysis and multiple regression analysis have been conducted to test the research hypotheses. The findings revealed that travellers' awareness and feeling of comfort toward standard and elevated procedures positively influence their intention to re-travel. Whenever the awareness and feeling of comfort decreased, travellers intend to re-travel less through airports. It was also found that travellers' awareness and feeling of comfort toward racial profiling do not influence their intention to re-travel. Suggested recommendations and policy implications for airport security procedures and airports administrations are discussed.
\end{abstract}

Keywords: Terrorism, Airport Security, Air Passengers, Intention to Re-travel, Jordan.

Citation: Al-Saad, S., A. Ababneh and M. Alazaizeh (2019) The influence of airport security procedures on the intention to re-travel. European Journal of Tourism Research 23, pp. 127-141

\section{Introduction}

Tourism is the most susceptible industry to numerous terrorism threats and other criminal acts. The number of total terrorist incidents in the world has been doubled in the last ten years from 4805 in 2008 to 10900 in 2017 (Global Terrorism Database, 2018). Tourism has suffered from frequent terrorist's attacks (e.g., attacks on the World Trade Center and the Pentagon 2001), wars (e.g., Iraq 2003), and

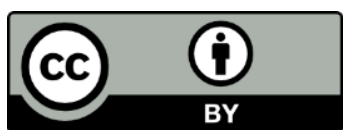

RESEARCH PAPER
This work is licensed under the Creative Commons Attribution 4.0 International (CC BY 4.0). To view a copy of this license, visit https://creativecommons.org/licenses/by/4.0/ 
political instability (e.g., Tunisia, Syria, Iraq, Yemen, Libya and Bahrain), which adversely impacted tourism performance, and contributed to some uncertainty, some hesitation, and the increase of doubtful perception of different destinations (Al-Saad \& Ababneh, 2017). According to the 2016 Global Terrorism Index, the contribution of the tourism industry to Gross Domestic Product (GDP) is twice as large in a county that has not suffered recently from terrorist attacks (Institute for Economics and Peace, 2016). Due to the perseverance and diversity in the implementation of the terrorist attacks, air transportation system has increasingly become more vulnerable for terrorist attacks than other systems, however, airport security must also adapt in line to protect the aviation industry and increase air passengers' safety. Consequently, demand for high-level security standards over the past two decades has witnessed a noticeable increase.

In response to such terrorist attacks, many countries modified their regulations and tightened significantly airport security procedures. Routinely, all passengers and flight crews are subject to standardized security procedures, which include baggage X-ray, body X-ray, metal detector scan, and passport control. In the wake of 11 September 2001 attacks, security procedures have become much stricter all over the world. For instance, on 19 November 2001, the United States Congress enacted the Aviation and Transportation Security Act (ATSA), which mandated several important changes in civil aviation security procedures (Blalock et al. 2007). Such changes and amendments came as a response to high elevated risks. O'Malley (2006) indicated that security procedures have become more commonplace when there are elevated risks or suspicious behaviours like perspiration or fidgeting. They might include bodily pat-downs, bag searches and explosive trace detection scans (as cited in AlardsTomalin, 2014), as well as sniffing passengers by dogs and inspecting the contents of their laptops and cameras.

In some suspicious cases, passengers are singled out based on name, nationality, race, religion, ethnicity or physical appearance and subject them to an extreme vetting process and very long interrogation. After the appearance of the Islamic State of Syria and Iraq (ISIS) and its continuous terrorist attacks on different places around the world, some countries started to consider racial profiling as part of the counterterrorism plans. For example, on 27 July 2017, Executive Order 13769, titled 'Protecting the Nation from Foreign Terrorist Entry into the United States', has been signed to deny visitors from 6 Muslim countries from entering the United States for 120 days (The New York Times, 2017). Halter (2002) found that Arab Americans, people of Middle Eastern descent, and Muslims are being targeted for more tightened security measures at airports. Furthermore, according to a USA Today-Gallup Poll (2006), Americans favour more tightened security measures with Muslims. Nearly more than one third, $31 \%$, expressed that they would feel nervous if they see a Muslim flying on the same flight as themselves (Saad, 2006).

The relationship between airport security and travel and tourism industry is considered recently one of the most important areas for research. "Concerns for safety and security remain an important issue for the travel and tourism industry" is one of the ten important world tourism issues for 2018 (Edgell, 2018). Although airport security procedures and racial profiling enhanced the safety of passengers worldwide, they have made passengers feel uncomfortable, especially those suspected or targeted based on a stereotype on their ethnicity or race. Hasisi et al. (2012) found that Arab Israelis hold a significantly negative attitude towards the treatment of the security staff they perceived, while Jewish Israeli hold a positive one. Only $61.2 \%$ of Arab passengers reported that the security inspectors treated them like any other passenger compared with 90.3\% among Jewish passengers. Hernandez (2007) has also found that Afro-Americans and Hispanics are more likely selected for security checks than whites. Middle Easterners, on the other hand, are often felt less likely to be selected. Blackwood et al. (2013) argued that such treatment can raise a painful question about how they are seen and positioned by other passengers. These findings indicate that indignity incurred during security procedures by Arab passengers may made them feel uncomfortable, which subsequently had a 
negative impact on their return intention, particularly if their principal purpose of travel is tourism.

Although different studies have been conducted in different countries of the world to examine tourists' perception of security and associated experience at airports (Arana \& Leon, 2008), investigating perceptions toward airport security and its influences on the behavioural intention to re-travel in the Middle East suffers from a limited academic studies and lack of careful attention. The national aviation and airports authorities have put in place different security measures designed to protect both airport terminals and travellers from any terrorist incidents (Blalock et al. 2007, Alards-Tomalin et al. 2014). However, there is a paucity of perception studies on the security process at the national airports. There is a growing interest of published research on tourism in the Middle East especially with reference to tourism in conflict areas (Buda, 2016). Most of literature on tourism in the Middle East focus on issues such as political instability and their negative impacts (Buda, 2016), the influence of terrorist incidents on the tourism activities and calling for developing security measures with no prior research attention paid to safety at airports and how travellers perceive these security procedures regarding air travel. In addition, some prior researches conducted about security and safety at airports focused on the awareness, threat to dignity, and enplanement intentions (Alards-Tomalin et al. 2014; Turtugulov, 2009) but no one included all these variables (awareness, feeling of comfort and intention to re-travel) in one research. Therefore, this research has come up with new knowledge in this field of study to fill the gap on literature by understanding the perceptions of Jordanian international travellers toward airport security procedures (whether standard, elevated or racial profiling) and how that influence their intention to re-travel. In addition, this research attempts to examine the differences of international travellers, according to their sex, marital status, age, educational level, employment status, household income, frequency of travel, and length of airport security check.

\section{Literature Review}

The concepts of security and safety have been defined in numerous ways in the literature. Generally, the word 'security' means freedom from danger, risk, doubt, or threat (Boholm, Möller, \& Hansson, 2016; Wilks, 2006). Sadatsafavi et al. (2019) defined security as a protection from terrorism, piracy and/or organised crime. The word safety is defined in The Oxford Advanced Learner's Dictionary (2007) as the state of being safe and protected from danger and harm. Within the realm of tourism, security and safety encompass the protection of people physically and the image of the environment of a tourist destination (Cadavez, 2016; Tarlow, 2009; Costea, Hapenciuc \& Stanciu, 2017).

Perceived feeling of comfort towards destination's security in general and airports is a significant factor influencing the choice of a destination (Peters \& Papathanassis, 2019; Chi \& Qu, 2008; Quintal \& Polczynski, 2010). Several studies have suggested different factors that have an important influence on the perceived feeling of comfort toward a destination and airports. Tourist based attributes such as visitor's previous experience, exposure to previous crime incident, and demographic characteristics are playing a relatively important role in perceptions of risks (Adeloye \& Brown, 2018; Carballo, León \& Carballo, 2017; Garg, 2015; Batra, 2008; George, 2003). For instance, it was found that variables such as nationality, gender, age have major influence on the international tourists' perceptions and concern for safety, security and risks (Garg, 2015; Batra, 2008).

Lack of awareness about security issues is considered one of the most important factors leading to security incidents (Nilsen, Albrechtsen \& Nyheim, 2018; Furnell, 2007). In many cases, tourists may have not taken part in any tourism activities or even return to a tourist destination if they feel unsafe (Adeloye \& Brown, 2018; George, 2003). In a research conducted to investigate the perceptions of American and European travellers towards the security and safety in air travel, the findings revealed that respondents are aware of the importance of safety and security in air travel. $70 \%$ of respondents strongly agreed that 
airport security procedures are important today because of previous terrorist attacks. The majority of Americans (74\%) and Europeans (76\%) agreed that introducing improved screening technology would ease concerns over safety, however, some of them (55\%) stated that this introduction would increase wait time at checkpoints and cause possible delays (Essays, UK, 2015).

Nevertheless, in a quantitative based study looking at Malaysian nationality and passengers with non-Malaysian nationality awareness and perception on airport safety and security measures and procedures, Turtugulov (2009) found that perception of Malaysian passengers regarding airport safety and security measures and procedures is higher than non-Malaysian. The study found that factors of age group, ethnicity and previous experience played an important role. Reisinger and Mavodno (2005) concluded that travellers from countries such as the USA, Australia and Hong Kong, were likely to perceive more international travel associated risk and treats. Thus, as part of national tourism development strategy, countries such as Germany and Australia have developed national visitor programs aiming at improving visitor safety awareness (Destination NSW, 2016).

\section{Hypotheses Development}

As mentioned earlier, several studies have been published on the context of security and safety at airports. Most of the researchers focus on safety incidents impacts, while little attention has been given to understand travellers' awareness and perceived feeling of comfort toward airport security. In terms of awareness toward airport security procedures, a study conducted after the events of September 11, 2001; American and British travellers showed that they are concerned with and aware of airport security procedures and issues, although they indicated that they are little worried about air travel (FrederickRecascino et al. 2003). However, to date, the relationships between the awareness of international travellers towards airport security procedures and their intention to re-travel is still unexamined in the literature. Therefore, the present research is an attempt to fill the gap in knowledge about how awareness might influence travellers' intention to re-travel. Hence, this research hypothesized that awareness towards airport security procedures positively influence travellers' intention to retravel (H1). Secondly, it hypothesized that awareness toward standard airport security procedures positively influence travellers' intention to re-travel (H1a). Thirdly, it hypothesized, that awareness toward elevated airport security procedures positively influence travellers' intention to re-travel (H1b). Lastly, it hypothesized that awareness toward racial profiling airport security procedures positively influence travellers' intention to re-travel (H1c).

However, in tourism research different factors were identified as drivers of intention to retravel to a specific destination (Kozak, 2001). Those factors are for example quality of service (Chen, 2008), tourism operator performance (Oh, 1999) consumer's needs (Chen \& Paliwoda, 2004) perceived risk (Quintal \& Polczynski, 2010) and personal values (Ekinci \& Chen, 2001).

Beck et al. (2017) have recently examined the perceptions of how safe airline travel is and the respondents' level of concern over privacy and trust of authorities. They found that people who trust authorities are more likely to travel internationally, while those with low feelings of safety are inclined not to travel. Also, Barros and Assaf (2012) found that different destination-based attributes such overall quality; reputation and safety have a positive impact on the returning intention. The security at airports has a major impact on the intention to return of travellers. The impact of the airport security procedures and associated staff on passengers while travelling was shown to be crucial variable of airport performance and noteworthy topic for passengers' satisfaction.

The inconvenience of security procedures reduces passenger demand for air travel. In a study conducted by Blalock et al. (2007) about the impact of post $9 / 11$ airport security measures on the demand for air travel in the United States, it was found that tightened airport security, in response to $9 / 11$ attacks, had the unintended consequence of reducing the convenience of air travel, which in turn caused a decline in the demand for air travel. 
Security screening reduced passenger volume by about $5 \%$ on all flights, and by about $8 \%$ on flights departing from the nation's fifty busiest airports which comprise more than $80 \%$ of the total passenger volume in the U.S.

Moreover, a few researchers in the field of tourism argue that airport security procedures have an important impact on the intention to retravel. However, travellers correlate some disrespect and humiliation practices by security personnel at airports. In their study, AlardsTomalin et al. (2014) examined the perceptions of leisure travellers attending a Canadian university towards the influence of airport security measures on enplanement intentions. Based on their findings, in which the perceived dignity threat for both standard and elevated security procedures exhibit significant negative relationships with intentions to use commercial air carriers in the future, we hypothesized that travellers' feeling of comfort toward airport security procedures positively influence their intention to re-travel (H2). Secondly, we hypothesized that travellers' feeling of comfort toward standard airport security procedures positively influence their intention to re-travel (H2a). Thirdly, we hypothesized that travellers' feeling of comfort toward elevated airport security procedures positively influence their intention to re-travel $(\mathbf{H} \mathbf{2 b})$. On the other hand, racial profiling appears to be more uncomfortable airport security procedures. For instance, the analysis made by Blackwood et al. (2013) regarding Scottish Muslims concerning their encounters at airports showed that airports were considered as places of humiliation, distress and, in some cases fear. Based on this finding, we hypothesized that travellers' feeling of comfort toward racial profiling airport security procedures positively influence their intention to re-travel $(\mathbf{H} 2 \mathrm{c})$.

\section{Methodology}

Quantitative research method was used to understand the Jordanian international travellers' awareness and feeling of comfort towards airport security procedures (standard, elevated and racial profiling/human treatment) and how they influence their intention to retravel. A sample of Jordanian travellers were asked to complete a self-administrated questionnaire inquiring about their awareness and feeling of comfort towards the airport security procedures (standard, elevated, and racial profiling/human treatment), and their intention to re-travel. The responses were collected and analysed to understand how these perceptions may influence their intention to re-travel. Originally, the questionnaire was developed in English, and then translated into the national language of the country (Arabic) by a translation specialist.

\section{Data Collection}

Individuals over the age of 18 years and who have travelled in at least one international flight were the target population. Using convenience sampling technique, a total number of 400 questionnaires were delivered and 320 usable cases were obtained, resulting in a response rate of $80 \%$.

The data collection for this research included primary and secondary sources of data. The research began with collecting secondary information from different written and published sources, such as: books, journals, official documents, and online resources. The primary data were collected by asking Jordanians in key public areas to complete a selfadministrated questionnaire that included two parts with 48 items. The first part was designed to measure how respondents' awareness and feeling of comfort towards airport security procedures influence their intention to re-travel, while the second was to find out the sociodemographic characteristics of respondents such as sex, marital status, age, level of education, employment status, income, travel frequency, airport location and time length of security check.

\section{Measurement scales}

Gathering information on targeted variables is maximized by using six or seven response categories, allowing for greater differentiation in responses (Willits, Theodori, and Luloff, 2016). Although there has been noticeable scientific debate for decades over reliabilities of scales with two, three, five, seven, and nine response categories, many researchers argued that reliability of results is maximized by using seven-point scales (Cohen, Manion, and Morrison, 2000; Finstad, 2010). 
In addition to some personal information questions, the questionnaire included another three questions. The first question aimed to understand the travellers' level of awareness toward different types of airport security procedures (standard, elevated, and racial profiling/human treatment). By using 7-point Likert scaled question ranged from 1 (Not at all important) to 7 (Extremely important), respondents were asked to rate the degree of importance of different airport security procedures (standard, elevated, and racial profiling/human treatment). The second question of the questionnaire aimed to measure travellers' feeling of comfort toward the same airport security procedures. Respondents were asked to indicate to what extent they feel comfort with the airport security procedures. Respondents evaluated each security procedure on a 7-point Likert scaled questions ranging from 1 (very uncomfortable) to 7 (very comfortable). Questionnaire items for these two questions were adapted from AlardsTomalin (2014), Turtugulov (2009), Reisig et al. (2007), Colquitt (2001), Hasisi et al. (2012), Blackwood (2015), Johnson, et al. (2011), and Tyler and Wakslak (2004).

The third question included a group of statements to measure respondent's intention to re-travel again after experiencing the airport security procedures. Item responses were obtained on a 7-point Likert scale, responses ranged from 1 (strongly disagree) to 7 (strongly agree), respondents were asked to rate how much they agree with these statements. Questionnaire items for this question were adapted from Cole and Chancellor (2009), Prosser (1998), Huang and Hsu (2009), Shonk (2006), and Goeldner and Ritchie (2012). After conducting a Pilot Test with 30 passengers who had experience in international air travel, including business, visiting friends or relatives (VFR), other personal business, and pleasure, some of the questionnaire items were modified to be clearer and culturally valid.

\section{Data analysis}

The approach adopted in the current research included two types of data analysis: Confirmatory Factor Analysis and Multiple Regression Analysis. A confirmatory factor analysis (CFA) was used to analyse the statistical reliability and validity of the measurement models using EQS 6.1. Multiple Regression Analysis (MRA) was used to understand how awareness and feeling of comfort towards airport security procedures may influence travellers' intention to re-travel, and then conclude in the research hypotheses. The suggested model was then tested for goodness of fit (GOF).

Using IBM Statistical Package for the Social Sciences (SPSS) version 20.0, statistical analyses were conducted to test the research hypotheses, which were developed based on the planned research framework. Data were scanned and examined for outliers, missing values, and normality issues that could influence the results. 51 cases were identified and removed from the analysis as outliers. These outliers were removed because the data distribution was not normal. Maximum Likelihood Imputation with the Expectation maximization (EM) algorithm was used to impute missing values (Tabchnick \& Fidell, 2007).

\section{Results}

The quantitative findings of this research derived from questionnaire-based surveys distributed to Jordanian international travellers. The questionnaire allowed participants to express their viewpoints and perceptions of airport security procedures, and how they influence participants' intention to re-travel. Furthermore, the data was correlated and analysed based on several variables including sex, marital status, age, education level, employment status, household income, travelling frequency, airport location, duration of airport security check, and travel purpose. Using Cronbach's alpha, the total reliability for the summated scales was found to be above 0.85 (Awareness, 0.823; Feeling of comfort, 0.837 ; Intention to re-travel, 0.947) which was considered reliable (Churchill, 1979).

\section{Descriptive Analysis}

Firstly, a straightforward descriptive analysis was conducted on the personal information variables. As shown in Table 1, of the 269 surveys completed by the travellers, the largest group of respondents $(62.5 \%)$ were males. Regarding the age and marital status education 
of the sampled respondents, more than threequarters of them $(79.9 \%)$ were between the ages of $18-39$, with $56.5 \%$ being married. This came in line with the General Population and Housing Census conducted by the Jordan's Department of Statistics. It found that Jordan is a young society (population age 15-64 years $62.0 \%$ ) in 2017 (Department of Statistics, 2017). For educational attainment, the largest proportion of the sample $(60.2 \%)$ had undergraduate degree. More than half of the respondents $(67.3 \%)$ were employed, with monthly income less than JOD 1000 (68.1\%). As for the number of times they have travelled by air for the last five years, the results showed that approximately two thirds of the respondents $(60.9 \%)$ have travelled more than three times, and $60.6 \%$ of the respondent showed that time to complete airport security check was reasonable. Concerning travel purpose, $42.8 \%$ of the respondents have travelled for business, $25.7 \%$ for visiting family and friends, $15.2 \%$ for personal business, and $16.4 \%$ for pleasure. In terms of the location (continent) of airports which reflect respondents' perspectives toward airport security procedures, most of the respondents travelled through airports located in Asia $(45.0 \%)$, followed by Europe (37.5\%).

As shown in Table 2 and 3, respondents indicated that standard procedures are very important $(M=5.88, S D=1.22)$, and they feel comfort with them $(\mathrm{M}=5.38, \mathrm{SD}=1.50)$, while elevated and racial profiling are low to slightly important $(\mathrm{M}=3.13 \mathrm{SD}=1.60 ; \mathrm{M}=2.09, \mathrm{SD}=$ 1.67) and uncomfortable $(\mathrm{M}=2.76, \mathrm{SD}=1.51$; $M=2.18, S D=1.55)$. "Scanning bags by $X$-ray" $(\mathrm{M}=6.46, \mathrm{SD}=0.91)$ and "Controlling passport" $(M=6.19, S D=1.02)$ were considered the most important procedures for travellers. Scanning bags and body by X-ray was also considered the most comfortable $(\mathrm{M}=6.14, \mathrm{SD}=1.09$, $\mathrm{M}=5.70, \mathrm{SD}=1.47$ ).

Concerning the elevated procedures, "Stripsearch" was considered the least important item $(M=1.99, S D=1.42)$, followed by "Sniffing passengers by dogs" $(M=2.61, S D=1.60)$, and the item "Sniffing passengers by dogs" was also considered the most uncomfortable procedure $(M=2.33, S D=1.45)$, followed by "Strip-search" $(M=1.88, S D=1.30)$. In terms of

racial profiling / human treatment, "Singling out some passengers based on their ethnicity or race and sniffing them by dogs" was considered the least important item $(M=2.25$, $S D=1.59$ ), followed by "Singling out some passengers based on their ethnicity or race for strip-search" $(M=1.96, S D=1.45)$, while the item "Singling out some passengers based on their ethnicity or race and sniffing them by dogs" was also considered the most uncomfortable $(M=2.03, S D=1.49)$, followed by "Singling out some passengers based on their ethnicity or race for strip-search" $(M=1.84$, $\mathrm{SD}=1.41)$.

Table 1. Descriptive statistics of respondents

\begin{tabular}{|c|c|c|}
\hline Item & $\mathbf{N}$ & Percentas \\
\hline \multicolumn{3}{|l|}{ Gender } \\
\hline Male & 168 & 62.5 \\
\hline Female & 101 & 37.5 \\
\hline \multicolumn{3}{|l|}{ Marital status } \\
\hline Single & 114 & 42.4 \\
\hline Married & 152 & 56.5 \\
\hline Divorced & 3 & 1.1 \\
\hline \multicolumn{3}{|l|}{ Age } \\
\hline $18-28$ & 103 & 38.3 \\
\hline $29-39$ & 112 & 41.6 \\
\hline $40-50$ & 41 & 15.2 \\
\hline $50-60$ & 10 & 3.7 \\
\hline Above 60 & 3 & 1.1 \\
\hline \multicolumn{3}{|l|}{ Education } \\
\hline High school & 14 & 5.2 \\
\hline Two-year college & 15 & 5.6 \\
\hline Undergraduate & 162 & 60.2 \\
\hline Graduate & 78 & 29.0 \\
\hline \multicolumn{3}{|l|}{ Employment } \\
\hline Employed & 181 & 67.3 \\
\hline Unemployed & 74 & 27.5 \\
\hline Retired & 13 & 4.8 \\
\hline Missing & 1 & 0.4 \\
\hline \multicolumn{3}{|l|}{ Income (JD) } \\
\hline Less than 500 & 104 & 38.7 \\
\hline $501-1000$ & 79 & 29.4 \\
\hline $1001-1500$ & 45 & 16.7 \\
\hline Above 1500 & 39 & 14.5 \\
\hline Missing & 2 & 0.8 \\
\hline \multicolumn{3}{|c|}{ Number of flights last five } \\
\hline years & 57 & 21.2 \\
\hline One time & 48 & 17.8 \\
\hline Two times & 36 & 13.4 \\
\hline Three times & 128 & 47.5 \\
\hline Four times or $m$ & & \\
\hline \multicolumn{3}{|c|}{ Airport location } \\
\hline Asia & 121 & 45.0 \\
\hline Africa & 7 & 2.6 \\
\hline Europe & 101 & 37.5 \\
\hline Australia & 5 & 1.9 \\
\hline
\end{tabular}


The influence of airport security procedures on the intention to re-travel.

\begin{tabular}{|c|c|c|}
\hline & & \\
\hline Antarctica & 6 & 2.2 \\
\hline North America & 26 & 9.7 \\
\hline South America & 3 & 1.1 \\
\hline Time to complete airport & & \\
\hline security check & 12 & 4.5 \\
\hline Very short time & 49 & 18.2 \\
\hline Short time & 163 & 60.6 \\
\hline Reasonable time & 38 & 14.1 \\
\hline Long time & 7 & 2.6 \\
\hline Very long time & & \\
\hline Purpose of travel & & \\
\hline Business & 115 & 42.8 \\
\hline Visiting friends and relatives & 69 & 25.7 \\
\hline Personal business & 41 & 15.2 \\
\hline Pleasure & 44 & 16.4 \\
\hline Total & 269 & 100 \\
\hline
\end{tabular}

\section{Confirmatory Factor Analysis (CFA)}

Confirmatory Factor Analysis (CFA) using EQS

6.1 was used to examine the dimensionality and reliability of the items, and to identify the representative items. According to Kline (2011), the following goodness-of-fit indices were used to evaluate the model fit: Sattorra-Bentler ChiSquare $\left(\mathrm{SB} \mathrm{X}^{2}\right)$, Standardized Root Mean Square Residual (SRMR), Root Mean Square Error of Approximation (RMSEA), and Comparative Fit Index (CFI), Non-Normed Fit Index (NNFI). The initial models including all items produced unsatisfactory results because of unacceptable fit indices. A number of multidimensional and potentially poor items were removed according to the Lagrance Multiplier Test (LM-Test). The indices for the initial and final models are shown in Table 2 and 3 . The fit indices for the final models were all within acceptable ranges (Kline, 2011).

The Relationship between Awareness, Feeling of Comfort, and Intention to Re-travel

Generally, the results showed in Table 2 that travellers indicated that standard airport security procedures are very important $(\mathrm{M}=5.88, \mathrm{SD}=1.22)$. However, elevated and racial profiling procedures are low to slightly important $(\mathrm{M}=3.13 \mathrm{SD}=1.60 ; \mathrm{M}=2.09, \mathrm{SD}=$ 1.67). In addition, travellers indicated that they feel comfort with the standard airport security procedures $\quad(M=5.38, \quad S D=1.50), \quad$ and uncomfortable with elevated and racial profiling procedures $(M=2.76, \quad S D=1.51 ; \quad M=2.18$, $\mathrm{SD}=1.55)$. Travelers also indicated that after experiencing the different levels of airport security procedures, they intend to re-travel again $(\mathrm{M}=6.02, \mathrm{SD}=1.01$ ) (Table 3 ).

Multiple regression analysis was used to understand the effects of travellers' awareness and their feeling of comfort toward airport security procedures on their intention to retravel. As shown in Table 4, respondents' scores on the awareness and feeling of comfort toward the three levels of airport security procedures were used as independent variables (IVs), and respondents' scores on the intention to re-travel were used as dependent variable (DV).

The results revealed that, in general, there is no significant relationship between travellers' awareness toward airport security procedures, and their intention to re-travel ( $F=0.004$; $p<0.05)$. This result does not support Hypothesis 1. At the same time, the results indicated that travellers' awareness toward standard and elevated airport security procedures have significant positive effects on their intention to re-travel, with beta 0.174 $(p<0.05)$, and $0.181 \quad(p<0.05)$, that support the Hypotheses 1(a) and 1(b). This means that whenever the awareness toward the standard and elevated airport security procedures increased, travellers' intent to travel more. The results also showed that there is no significant relationship between the awareness toward racial profiling airport security procedures and the intention to re-travel. Therefore, Hypothesis 1 (c) was not supported.

Regarding travellers' feeling of comfort toward airport security procedures, the results showed that generally, there is no significant relationship between travellers' feeling of comfort and their intention to re-travel $(\mathrm{F}=0.015 ; \quad p<0.05)$. This does not support Hypothesis (2). However, the results indicated that feeling of comfort toward standard and elevated airport security procedures positively affect travellers' intention to re-travel, with beta $0.316(p<0.05)$ and $0.238(p<0.05)$. Therefore, Hypotheses 2(a) and 2(b) were accepted. Hypothesis 2(c) was rejected because the results indicated that there is no significant relationship between feelings of comfort toward racial profiling airport security procedures and the intention to re-travel. In addition, no signify- 


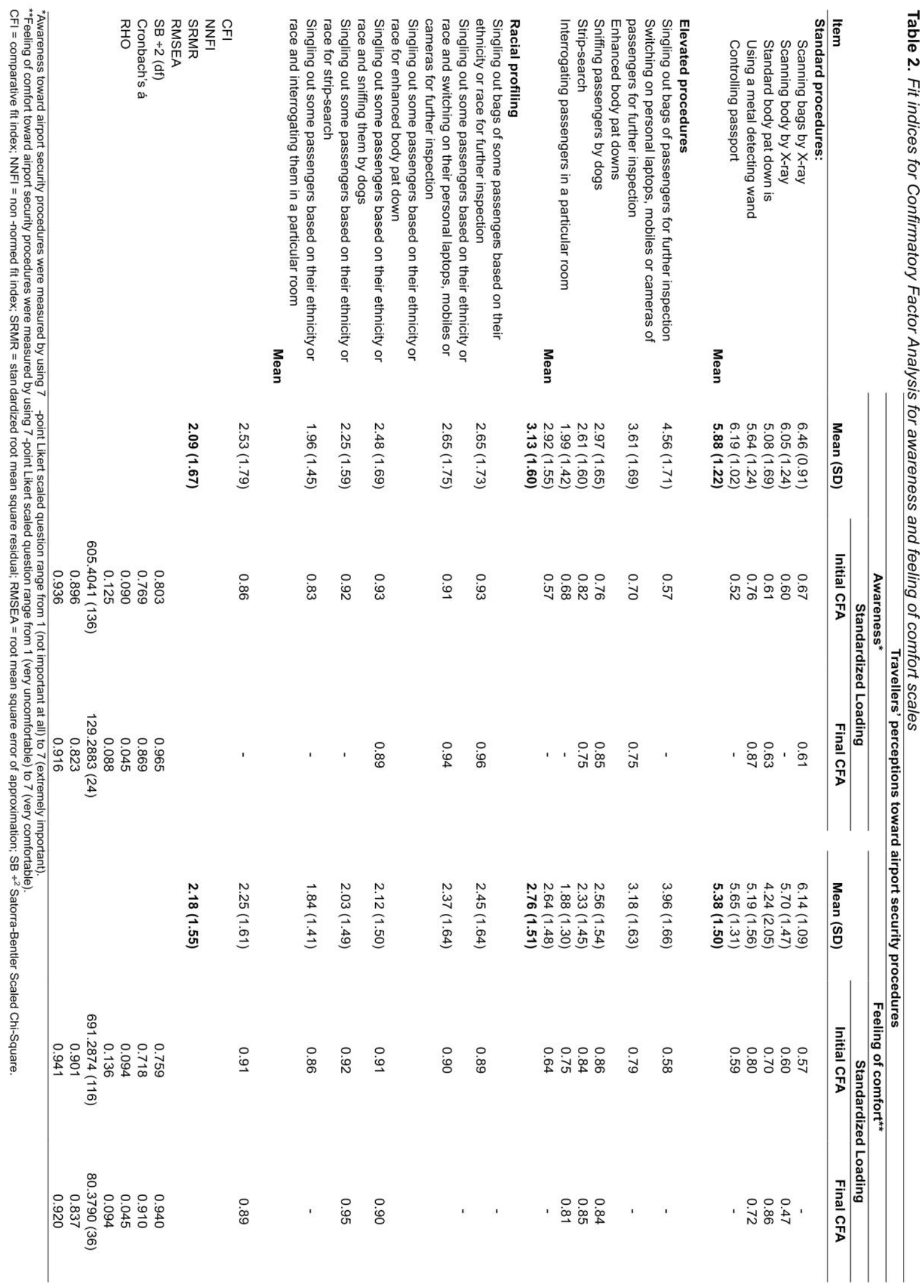


The influence of airport security procedures on the intention to re-travel.

Table 3. Fit indices for Confirmatory Factor Analysis for the intention to re-travel scale

\begin{tabular}{|c|c|c|}
\hline Item* & Mean (SD) & $\begin{array}{c}\text { Standardized Loadings } \\
\text { Initial/Final Model }\end{array}$ \\
\hline I intend to travel through airports again in the future & $6.15(1.01)$ & 0.81 \\
\hline I plan to travel through airports again in the future & $6.06(1.05)$ & 0.84 \\
\hline I desire to travel through airports again in the future & $6.08(0.99)$ & 0.87 \\
\hline I probably will travel through airports again in the future & $5.83(1.13)$ & 0.74 \\
\hline I would like to travel through airports again in the future & $5.99(0.93)$ & 0.89 \\
\hline I will travel through airports again in the future & $6.06(0.99)$ & 0.90 \\
\hline There is no doubt that I will travel through airports again in the future & $5.99(1.02)$ & 0.84 \\
\hline I recommend friends or relatives to travel through airports & $6.01(0.96)$ & 0.76 \\
\hline 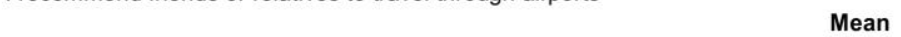 & $6.02(1.01)$ & \\
\hline CFI & & 0.971 \\
\hline NNFI & & 0.923 \\
\hline SRMR & & 0.027 \\
\hline RMSEA & & 0.073 \\
\hline$S B \div 2(d f)$ & & $48.2645(20)$ \\
\hline Cronbach's $\alpha$ & & 0.946 \\
\hline $\mathrm{RHO}$ & & 0.947 \\
\hline
\end{tabular}

*Intention to re-travel was measured by using 7-point Likert scaled question range from 1 (strongly disagree) to 7 (strongly agree)

$\mathrm{CFI}$ = comparative fit index; NNFI = non-normed fit index; SRMR = standardized root mean square residual; RMSEA = root mean square error of approximation; $\mathrm{SB} \div 2$ Satorra-Bentler Scaled Chi-Square.

Table 4. Results of multiple regression analysis

\begin{tabular}{lccccc}
\hline IVs & $\mathbf{B}(\mathrm{SE})$ & $\boldsymbol{\beta}$ & $\boldsymbol{t}$ & $\boldsymbol{R}^{\mathbf{2}}$ & $\mathbf{F}$ \\
\hline Awareness & $-\mathbf{0 . 0 0 3 ( 0 . 0 5 2 )}$ & $-\mathbf{0 . 0 0 4}$ & $\mathbf{3 1 . 0 6 6}$ & $\mathbf{0 . 0 0 0}$ & $\mathbf{0 . 0 0 4}$ \\
Standard & $0.137(0.052)$ & 0.174 & $5.049^{\star}$ & 0.350 & $10.524^{\star}$ \\
Elevated & $0.116(0.047)$ & 0.181 & $3.304^{*}$ & & \\
Racial profiling & $-0.028(0.35)$ & 0.053 & -0.526 & & \\
& & & & & \\
Feeling of comfort & $-\mathbf{0 . 0 0 6 ( 0 . 0 5 1 )}$ & $-\mathbf{0 . 0 0 8}$ & $\mathbf{- 0 . 1 2 3}$ & $\mathbf{0 . 0 0 0}$ & $\mathbf{0 . 0 1 5}$ \\
Standard & $0.199(0.039)$ & 0.316 & $2.646^{\star}$ & 0.106 & $3.168^{\star}$ \\
Elevated & $0.161(0.049)$ & 0.238 & $2.487^{\star}$ & & \\
Racial profiling & $-0.021(0.040)$ & 0. & 0.783 & & \\
\hline
\end{tabular}

Table 5. Evaluation of hypotheses

\begin{tabular}{cc} 
Hypothesis & Results \\
\hline H1: Awareness towards the airport security procedures positively influence travellers' intention to re-travel & Not supported \\
H1(a): Awareness toward standard airport security procedures positively influence travellers' intention to re-travel. & Supported \\
H1(b): Awareness toward elevated airport security procedures positively influence travellers' intention to re-travel. & Supported \\
H1(c): Awareness toward racial profiling airport security procedures positively influence travellers' intention to re-travel & Not supported \\
& \\
H2: Travellers' feeling of comfort toward airport security procedures positively influence their intention to re-travel & Not supported \\
H2(a): Travellers' feeling of comfort toward standard airport security procedures positively influence their intention to re-travel. & Supported \\
H2(b): Travellers' feeling of comfort toward elevated airport security procedures positively influence their intention to re-travel. & Supported \\
c): Travellers' feeling of comfort toward racial profiling airport security procedures positively influence their intention to re-travel. & Not supported \\
\hline
\end{tabular}

cant relationship was found between the IVs and the DV when the general and personal variables (shown in Table 1) were considered.

\section{Discussion and Conclusion}

The present research makes a distinct and significant contribution to knowledge and literature in that it is the first to examine three levels of airport security procedures: standard, elevated and racial profiling/human treatment independently in one single model. Racial profiling was not considered by previous studies on intention to re-travel. In addition, it is the first one conducted in a region of political instability.

Examining overall perceptions of travellers toward airport security procedures, it was found that there is agreement that standard procedures are important and comfortable. Jordanian travellers believe that these procedures can protect them from accidental/malicious harm, explosions, hijacking and other threats without causing 
inconvenience. It can be noticed that the least important elevated security procedures and racial profiling procedures were the most uncomfortable. This is due to that after the $9 / 11$ attacks, Arab passengers are more likely to be inspected by airport security staff than passengers from other nations. These findings contradict with the previous research in general because it has been indicated that after the 9/11 attacks, the passengers feel that the tightened airport security procedures become significantly more important (Hernandez, 2007). This contradiction may be attributed to that the cases of the two studies are American people who worry a lot about terrorism, support efforts to counter and prevent any possible future attacks. Their negative experience and structurally mapped cognition about terrorism and hijacking increased their awareness about the importance of higher and tighter airport security procedures.

Although air passengers consider safety is of ultimate importance as they pay not only for airplanes but also for the cost of the security procedures (Sakano et al. 2016), these procedures make passengers less convenient and cause assault on their dignity. Consequently, passengers currently consider airport security checkpoints as the most critical and stressful phase of their trip (AviationFacts.eu, 2017). It has been found in the literature that inconvenience and dignity assault influence demand of air travel (AlardsTomalin et al. 2014; Hasisi et al. 2012; Blackwood, 2015). In a model tested by AlardsTomalin et al. (2014), the perceived dignity threat caused by elevated airport security measures has much stronger negative relationships with enplanement intentions of travellers. In a related context, the model of the current research is the first to understand how travellers' awareness and their feeling of comfort toward airport security procedures influence their intention to re-travel. The results contradict with the previous research in general, as travellers indicated that after experiencing the different levels of airport security procedures (particularly racial profiling / human treatment), they intend to re-travel again $(M=6.02, S D=1.01)$.
In terms of awareness, the findings revealed that, in general, travellers' awareness toward airport security procedures does not influence their intention to re-travel. However, the results indicated that travellers' awareness toward standard and elevated airport security procedures influence their intention to re-travel. So, whenever the awareness toward the standard and elevated security procedures decreased, travellers' intention to re-travel less through airports, as they think these procedures are not necessary. This comes in line with the results of the study conducted by Beck et al. (2017). It was found that travellers who trust airport authorities more, intend to travel more internationally, while those who have relatively lower levels of overall safety while flying are inclined to not travel. Tightened security procedures do not only influence passengers but also influence airports and airlines. Blalock et al. (2007) confirmed that the $6 \%$ reduction of the number of air passengers in the United States is attributed to the new tighter baggage inspection after the $9 / 11$ attacks. As a result, airlines' profits fell significantly, as some prospective passengers opted to not travel by air (AviationFacts.eu, 2017). On the other hand, it was also found that travellers' awareness toward racial profiling at airports does not influence their intention to travel through airports. While people from most of the Arab and Islamic countries need to apply for visas in advance, some other nationalities can obtain visas on arrival. Because of the money they pay to get a visa, difficult procedures and many documents required, and time spent waiting for a visa, they are forced to afford the racial profiling procedures at airports. Dignity save would cost them much more money, tiredness and time.

Concerning travellers' feeling of comfort, the results showed that generally, travellers' feeling of comfort does not influence their intention to re-travel. Nevertheless, the results indicated that feeling of comfort toward standard and elevated airport security procedures positively affect travellers' intention to re-travel. Thus, whenever travellers feel less comfortable toward the standard and elevated security procedures, they intend to re-travel less through airports. As stated by Alards-Tomalin et al. (2014), elevated procedures introduce 
added concerns regarding the invasion of personal privacy, and the increasing probability for indignity and humiliation, which cause stronger negative relationship with enplanement intention. The research findings conclude that standard and elevated airport security procedures are important and uncomfortable today, as a reaction to the previous terrorist events, so low awareness of their importance and feeling uncomfortable toward the standard and elevated procedures would decrease travellers' intention to re-travel.

In contrast, it was found that travellers' feeling of comfort toward racial profiling procedures does not influence their intention to re-travel. Therefore, it can be said that although travellers believe that racial profiling procedures are unimportant and uncomfortable at all, they would intend to travel again by air. As mentioned earlier, that this is attributed to that most of the respondents are business travellers. Travelling for business is assigned to them and they have no choice, even they were singled out for differential human treatment or tighter scrutiny based on their ethnicity, race, religion or country of origin. Free trip is another possible explanation for our findings, because usually the costs of the business trips (flight tickets and accommodation services) as well as employees' allowances are paid by a second party, often the institutions or organizations employing them.

\section{Recommendations and Future Research}

With the accelerated increase of passengers' number and continuous terrorist threats all over the world, the administrations of airports enhanced the level of security and tightened scrutiny procedures. Those changes have negative impacts on the travel and tourism industry in general, and in particular, on passengers. Although passengers accept airport security procedures to ensure their safety from any attack, they are still the most inconvenient part during their travel. A number of studies stated that there is a permanent reduction in air travel attributed to the higher level of passengers screening. The findings of the research revealed to be important, as they demonstrate the opposite of what the previous literature found. In addition, it is the first to understand how travellers' awareness and their feeling of comfort toward airport security procedures (standard, elevated, and racial profiling) influence their intention to re-travel. Racial profiling was not considered by previous studies on intention to re-travel. Furthermore, it is the first one conducted in a region of political instability.

The results showed that travellers see that standard procedures are very important, and they feel comfort with them, while elevated and racial profiling are low to slightly important and uncomfortable. What makes a travel through airport problematic is the sense of indignity and injustice. Singling out some passengers based on their ethnicity or race for further inspection under the gaze of their fellow passengers would make their travel experience humiliating. This recommends that analysis of the sense of humiliation and indignity caused by elevated and/or racial profiling procedures need to pay more attention. Furthermore, the findings revealed that, whenever the awareness and feeling of comfort toward the standard and elevated security procedures decreased, travellers intend to re-travel less through airports. At this time, the administrations of airports should be aware that it is perceived that elevated and racial profiling cause dignity threat to passengers, and so influence the demand for air transport. Likewise, psychological and social statuses of people have been used to effectively predict overt behavioural intentions (Ajzen and Fishbein, 1980). Consequently, behavioural intention to re-travel is an essential indicator of flight ticket procurement behaviours, so, this needs to be further addressed. The administrations of airports should take this finding into consideration and change their daily orders and actions.

In terms of subjectivity of the airport security personnel in inspecting passengers and their baggage, a recent study revealed that some airport security staff tend to be biased in treating some passengers differently and singling them out for additional scrutiny checks (Blackwood et al. 2013), which negatively increased their feelings of humiliation, or dignity threat. What make it worse is that this happens in front of their fellow passengers. This study suggests that security officials should pay more attention to the analysis of identity dynamics 
and the experience of humiliation. On the other hand, airport security personnel should be better trained on the global ethics of travel and tourism in order to inspect passengers without threatening one's sense of dignity. They should also develop new programs that could maintain their focus on suspicious people regardless of their religion, race, ethnicity, or nationality. After all, their mission is to protect passengers and airports not to make them stressful or fearful when they travel.

The current research showed two main limitations. Firstly, the sample of this research consists of Jordanian international travellers. These people have a similar culture and beliefs to some extent, and nationality which makes the sample relatively homogeneous. Consequently, their findings could be generalized on the Arab and/or Islamic countries but could not be generalized internationally. Secondly, there were some other variables that were not included into the model of the current research that may also influence the travellers' intention to re-travel, like the economic situation of countries, inflation, disposable income of individuals, and change in flight ticket prices. Therefore, future research related to this topic should take these variables into consideration, which would noticeably influence intention to re-travel.

\section{References}

Adeloye, D., \& Brown, L. (2018). Terrorism and domestic tourist risk perceptions. Journal of Tourism and Cultural Change, 16(3), 217-233.

Ajzen, I., \& Fishbein, M. (1980). Understanding attitudes and predicting social behavior. Englewood Cliffs, NJ: Prentice Hall.

Alards-Tomalin, D., Ansons, T. L., Reich, T. C., Sakamoto, Y., Davie, R., LeboeMcGowan, J. P., \& Leboe-McGowan, L. C. (2014). Airport security measures and their influence on enplanement intentions: responses from leisure travellers attending a Canadian university. Journal of Air Transport Management, 37, 60-68.

Al-Saad, S., \& Ababneh, A. (2017). Concept, opportunities and challenges of urban tourism in the Arab world: Case studies of Dubai, Cairo and Amman. TOURISM - An International Interdisciplinary Journal, 65 (3), 361-375.
Arana, J., \& Leon, C. J. (2008). The impact of terrorism on tourism demand. Annals of Tourism Research, 35(2), 299-315.

AviationFacts.eu. (2017). Airport security from a passenger's perspective fact sheet. URL: http://aviationfacts.eu/uploads/thema /file_en/59a3ca1670726f7882040000/Airp ort_Security_from_a_Passenger_s_Persp ective_Fact_sheet.pdf (Accessed on 17.11.2018).

Barros, C., \& Assaf, A. G. (2012). Analysing tourism return intention to an urban destination. Journal of Hospitality \& Tourism Research, 36(2), 216-231.

Batra, A. (2008). Foreign tourists' perception towards personal safety and potential crime while visiting Bangkok. Anatolia, 19(1), 89-101.

Beck, M. J., Rose, J. M., \& Merkert, R. (2018). Exploring perceived safety, privacy, and distrust on air travel choice in the context of differing passenger screening procedures. Journal of Travel $R e$ search, 57(4), 495-512.

Blackwood, L., Hopkins, N., \& Reicher, S. (2013). I know who I am, but who do they think I am? Muslim perspectives on encounters with airport authorities. Ethnic and Racial Studies, 36(6), 1090-1108.

Blackwood, L. (2015). Policing airport spaces: The Muslim experience of scrutiny. Policing, 9(3), 255-264.

Blalock, G., Kadiyali, V., \& Simon, D. (2007). The impact of post-9/11 airport security measures on the demand for air travel. The Journal of Law \& Economics, 50(4), 731-755.

Boholm, M., Möller, N., \& Hansson, S. O. (2016). The concepts of risk, safety, and security: applications in everyday language. Risk Analysis, 36(2), 320-338.

Buda, D. M. (2016). Tourism in conflict areas: complex entanglements in Jordan. Journal of Travel Research, 55(7), 835-846.

Cadavez, C. (2016). Tourism and terrorism: protecting paradise. Aviation Security International, 1(22), 28-30.

Carballo, R. R., León, C. J., \& Carballo, M. M. (2017). The perception of risk by international travellers. Worldwide Hospitality and Tourism Themes, 9(5), 534-542.

Chen, C. F. (2008). Investigating structural relationships between service quality, 
perceived value, satisfaction, and behavioural intentions for air passengers: evidence from Taiwan. Transportation Research Part A: Policy and Practice, 42(4), 709-717.

Chen, J., \& Paliwoda, S. (2004). The Influence of company name in consumer variety seeking. Journal of Brand Management, 11(3), 219-231.

Chi, C., \& Qu, H. (2008). Examining the structural relationships of destination image, tourist satisfaction and destination loyalty: an integrated approach. Tourism management, 29(4), 624-636.

Churchill, G. (1979). A paradigm for developing better measures of marketing constructs. Journal of Marketing Research, 19(4), 491-504.

Cohen, L., Manion, L., \& Morrison, K. (2002). Research methods in education. Routledge.

Cole, S. T., \& Chancellor, H. C. (2009). Examining the festival attributes that impact visitor experience, satisfaction and re-visit intention. Journal of Vacation Marketing, 15(4), 323-333.

Colquitt, J. (2001). On the dimensionality of organizational justice: a construct validation of a measure. Journal of Applied Psychology, 86(3), 386-400.

Costea, M., Hapenciuc, C. V., \& Stanciu, P. (2017). Tourist safety and security: a factor of the competitiveness of secondary tourist destinations. Revista de turismstudii si cercetari in turism, (23).

Destination NSW. (2016). Visitors safety and security.URL: https://www.destinationnsw. com.au/tourism/industry-opportunities/ visitor-safety-and-security (Accessed on 19.8.2018).

Department of Statistics. (2017). Jordan in figures. URL: http://dosweb.dos.gov.jo/ Data Bank/JordanInFigures/JORINFIG Details2017.pdf (Accessed on 9.11.2018).

Edgell, D. (2018). The ten important world tourism issues for 2018. URL: https://www.travelmole.com/news feature. php?news id=2028620 (Accessed on 28.7.2018).

Ekinci, Y., \& Chen, J. S. (2001). Segmenting overseas British holidaymakers by personal values. Journal of Hospitality \& Leisure Marketing, 9(3-4), 5-15.
Essays, UK. (2015). The airport security and safety in air travel tourism essay. URL: https://www.ukessays.com/essays/tourism /the-airport-security-and-safety-in-airtravel-tourism-essay.php (Accessed on 20.8.2018)

Finstad, K. (2010). Response interpolation and scale sensitivity: evidence against 5-point scales. Journal of Usability Studies, 5(3), 104-110.

Frederick-Recascino, C., Greene, F., Burns, C., \& Flin, R. (2003). Airport security: post 911 attitudes of US and UK travelers. Paper presented at the AIAA's 3rd Annual Aviation Technology, Integration, and Operations $\left(\right.$ ATIO) Forum, $17^{\text {th }}-19^{\text {th }}$ November 2003, Denver, Colorado.

Furnell, S., 2007. From the Editor-in-Chief: IFIP workshop-Information security culture. Computers and Security, 26(1), 35.

Garg, A. (2015). Travel risks vs tourist decision making: a tourist perspective. International Journal of Hospitality \& Tourism Systems, 8(1), 1-9.

George, R. (2003). Tourist's perceptions of safety and security while visiting Cape Town. Tourism Management, 24(5), 575585.

Global Terrorism Database. (2018). Number of terrorist incidents. URL: https://www.start.umd.edu/gtd/ (Accessed on 19.2.2019).

Goeldner, C. R., \& Ritchie, J. B. (2012). Tourism: principles, practices, philosophies (No. Ed. 12). New Jersey: John Wiley and Sons, Inc.

Halter, K. (2002). Flying while brown. The Washington Report on Middle East Affairs, 21(6), 85.

Hasisi, B., Margalioth, Y., \& Orgad, L. (2012). Ethnic profiling in airport screening: lessons from Israel, 1968-2010. American Law and Economics Review, 14(2), 517560.

Hernandez, E. (2007). Airport security: study of students' perception and knowledge of the selection of airline passengers for personal searches. Master Thesis. ProQuest.

Huang, S., \& Hsu, C. H. (2009). Travel motivation: linking theory to practice. International Journal of Culture, Tourism and Hospitality Research, 3(4), 287-295. 
Institute for Economics and Peace. (2016). Global Terrorism Index 2016. URL: http://economicsandpeace.org/wp-content /uploads/2016/11/Global-Terrorism-Index2016.2.pdf (Accessed on 19.2.2019).

Johnson, D., Brazier, D., Forrest, K., Ketelhut, C., Mason, D., \& Mitchell, M. (2011). Attitudes toward the use of racial/ethnic profiling to prevent crime and terrorism. Criminal Justice Policy Review, 22(4), 422-447.

Kline, R. B. (2011). Principles and practice of structural equation modelling. New York, NY: Guilford Press.

Kozak, M. (2001). Repeaters' behaviour at two distinct destinations. Annals of Tourism Research, 28(3), 784-807.

Malley, P. (2006). Risks, ethics, and airport security. Canadian Journal of Criminology and Criminal Justice, 48(3), 413-421.

Nilsen, M., Albrechtsen, E., \& Nyheim, O. M. (2018). Changes in Norway's societal safety and security measures following the 2011 Oslo terror attacks. Safety Science, 110, 59-68.

Oh, H. (1999). Service quality, customer satisfaction, and customer value: a holistic perspective. International Journal of Hospitality Management, 18(1), 67-82.

Oxford Advanced Learner's Dictionary 7th Edition. (2007). Oxford University Press.

Peters, L. A., \& Papathanassis, A. (2019). Security perceptions of tourists in the aftermath of terrorist attacks. In Papathanassis, A., Katsios, S., Dinu, N. (eds.) (2019). Yellow Tourism. Tourism, Hospitality \& Event Management. Cham: Springer, 83-98.

Prosser, R. (1998). Tourism. In Chadwick, R. F. (eds.) (1998). Encyclopedia of Applied Ethics, Vol. 4. San Diego, CA: Academic Press, 373-401.

Quintal, V., \& Polczynski, A. (2010). Factors influencing tourists' revisit intentions. Asia Pacific Journal of Marketing and Logistics, 22(4), 554-578.

Reisig, M., Bratton, J., \& Gertz, M. (2007). The construct validity and refinement of process-based policing measures. Criminal Justice and Behavior, 34, 1005-1028.

Reisinger, Y., \& Mavondo, F. (2005). Travel anxiety and intentions to travel internationally: implications of travel risk perception. Journal of Travel Research, 43, 212-225.

Saad, L. (2006). Anti-Muslim sentiments fairly commonplace. The Gallup Poll. URL: https://news.gallup.com/poll/24073/antimu slim-sentiments-fairly-commonplace.aspx (Accessed on 12.3.2019).

Sadatsafavi, H., Kim, A. A., Anderson, S. D., \& Bishop, P. (2019). Scenario planning application in us highway transportation industry. Journal of Infrastructure Systems, 25(2), 05019002.

Sakano, R., Obeng, K., \& Fuller, K. (2016). Airport security and screening satisfaction: A case study of US. Journal of Air Transport Management, 55, 129-138.

Shonk, D.J., 2006. Perceptions of service quality, satisfaction and the intent to return among tourists attending a sporting event (Doctoral dissertation, The Ohio State University).

Tabachnick, B. G., \& Fidell, L. S. (2007). Using multivariate statistics. Allyn \& Bacon/Pearson Education.

Tarlow, P. E. (2009). Tourism safety and security. The SAGE Handbook of Tourism Studies, 464-480.

The New York Times. (2017). Trump's order blocks immigrants at airports, stocking fear around globe. URL: http://www. nytimes.com/2017/01/28/us/trumps-immig ration-ban-disapproval-applause.html? rref=collection\%2Fsectioncollection\%2Fus (Accessed on 28.6.2018).

Turtugulov, A. (2009). Passengers awareness and perceptions on safety and security measures and procedures in airport terminal building (Doctoral Dissertation, Universiti Teknologi Malaysia).

Tyler, T. R., \& Wakslak, C. J. (2004). Profiling and police legitimacy: procedural justice, attributions of motive, and acceptance of police authority. Criminology, 42(2),253-282.

Wilks, J. (2006). Current issues in tourist health, safety and security. In Wilks, J., Pendergast, D., \& Leggat, P. (eds.) (2006). Tourism in turbulent times: toward safe experiences for visitors. Oxford, UK: Elsevier, 3-18.

Willits, F. K., Theodori, G. L., \& Luloff, A. E. (2016). Another look at Likert Scales. Journal of Rural Social Sciences, 31(3), 126. 